\title{
Discussing Tourism Security Syllabuses in Argentina
}

\author{
Maximiliano Korstanje \\ University of Palermo, Buenos Aires, Argentina
}

\begin{abstract}
The present essay review explores the anthropological reason why the curricula in Argentina are not enriched with tourism security options. Students no matter if they are in pre- or post-graduate courses go to long-established universities to study tourism as a valid career to find a rapid employment. Although in English-speaking societies, the security was included in the most important syllabuses, no attention is given to this in Argentina. Certainly, the main thesis that this project presents is that Spanish- and English-speaking countries have developed diverse strategies to adapt to risk conditions.
\end{abstract}

Keywords: education, syllabuses, risk, English-speaking countries

\section{Introduction}

One of the most problems that policymakers often face in their careers is associated with the volatility of tourism, as an industry which is based on the intangible world of experience (Korstanje \& Skoll, 2014). In contexts of crises, the communication of risk plays a vital role in avoiding the decline of a tourist destination. Senior sociologist, Cass Sunstein, has called the attention to the problem of risk to be dully interpreted beyond the monopoly of knowledge of experts (Tarlow, 2000; Korstanje, 2014a). Crises often destroy the reputation of tourist destinations.

Since we are governed by emotions, not surprisingly, our behaviors are led to over-valorize some risks, while others are undermined (Sunstein, 2002; 2005). A correct planning of risk communication process consists in evaluating all reasonable factors which may determine the probabilities of new unmanageable risks. The precautionary platform doctrine, encouraged by the European states, not only does not resolve the problem but also accelerates the volume of claims issued by citizenship to be addressed by state with efficiency (Sunstein, 2005). Some risks surface despite the governmental attempts to mitigate them. The nuclear energy and accidents as Chernobyl are examples of this. The same technology used to make the life of people safer resulted in a disaster. This is what specialists call the "paradox of risk". Why passengers are frightened to embark in a plane while driving risks are ignored?

In earlier studies, Korstanje has argued that the concept of security is based on the ability and capacity of community to give responses to certain problems. While the state can fulfill all quests to grant the perception of well-being for community, major cognitive dissonances appear. The governance is based on the efficiency of the state to reduce uncertainty. Whenever the sense of control in society is defied, panic emerges. Though statistics reveal how safe the airplanes are with respect to other means of transport, we sat in the plane without any opportunity to take control of our itinerary. We are subject to the other's skill to operate the aircraft; rather, our anxieties are reduced while we drive in the roads, though the probabilities to suffer an accident rise

Maximiliano Korstanje, Dr. (Tourism), Department of Economics, University of Palermo. Email: Mkorst@palermo.edu. 
(Korstanje, 2009; Korstanje \& Olsen, 2011; Korstanje \& Clayton, 2012). This is the reason why the process of communication is of paramount importance to do a correct diagnosis that would lead experts to implement an efficient risk management program (Floyd \& Pennington-Gray, 2004).

In this respect, Faulkner (2001) emphasized the needs to activate communicative programs that educate practitioners and professionals in the risk management programs. The responsibility to save lives depends on the ability to implement coherent course of actions to mitigate disasters and improve the guidelines for rescue training. Quintal, Lee, and Soutar (2010) explained that the future of tourism industry is associated with the differential impacts of risk in public opinion. The perceiving risk influences may affect the image and reputation of a destination, declining its attractiveness for the international demands. The over-abundance of specialized literature and risk and communication exceeds our space and time in this manuscript. The greater the dependency of community with tourism is, the more vulnerable the destination is.

Hence, it is not the intention, in this essay review, to theorize about the nature of risk, nor the perception or its evolution. For tourism fields, what is important to discuss is to what extent Argentinian universities include in their programs syllabuses with regard to risk management, crises management, communication, or tourism security. On one hand, students today are not receiving necessary training to conduct risk management plans at the universities; this faculty is being reserved by the forces of security such as Police or Gendarmerie. Even the specialists of tourism security are not been recruited from the educational establishments, they are retiree police commissioners. On the other hand, the economic problems such as the lack of investments and inflation urged many citizens make holidays in other countries. The current demands of tourism in Argentina rest on the neighboring countries, Europe, and America.

Why universities do not offer their students security courses or syllabuses in neither Argentina nor the rest of Latin America? An alternative answer to this, as some scholars embrace, is that the stage of securitization that the world is facing today post-9/11 is not a concern of Argentinians. Instead of focusing on the problems of international terrorism which targets international tourists or the natural disasters, citizens in this austral country are concerned with other problems, such as political corruption, the local crime, and unemployment (Kessler, 2009). Despite suffering two important bombings in Buenos Aires that killed 80 victims, terrorism is even viewed by social imaginary as a problem of developed countries, the United States, and Europe. The fact that not only Argentina rejected the opportunity to integrate international alliance to fight against terrorism in the world but also Israel's embassy which suffered serious losses were relocated in new boroughs after the attack made citizens believe that Argentina is not a selected target for terrorists (Korstanje \& Skoll, 2012). To some extent, terrorism is viewed by the media as a resulted responsibility of the nation-states actions in the international arena. Quite aside, from this, the problem Argentineans frighten, even by tourists, is the local crime. However, since all hotel chains are allocated in the most selective borough of urban cities, which are reinforced by strong measures of security and police, specialists (some of them coming from Police) consider that the security of tourists is controlled. A second explanation to the same question consists in the marginal contribution of tourism to the local GDP of mega cities. Though tourism is an important source of fresh incomes for the country, the new jobs were created after 2001 which are related to the company manufacturers of vehicles and exporters of raw materials. The lack of maturation of tourism industry in comparison with other Latin American destinations, conjoined with problems of infrastructure, makes tourism not a real priority of government, beyond its naive discourses. To date, almost 60 careers associated with tourism and hospitality lack tourism security as a primary or secondary program in pre- and post-graduate careers. 
The third viewpoint here deserves to be discussed. First and foremost, we strongly believe that practitioners, politicians, and even policymakers are concerned about how risks may affect the tourist destinations and their local economies. A couple of weeks back (September 2014), a young Canadian biker was shotgunned in the borough of La Boca, while he was touring through Buenos Aires city. In question of days after this event, a hot debate in the most important TV programs reinforced the long simmering claims of further security at the streets. On the basis of this, people expressed their opinions in blogs, Twitter, Facebook, and other multimedia supporting the Canadian visitors who returned home unharmed. The treatment dispensed to a tourist says more to the world than thousands of promotional campaigns. The bad experience that this tourist faced reflects the image of Argentina in the world. This affected, per bloggers and cybernauts, not only our right to give hospitality to strangers but also our image as a "civilized country". Nonetheless, the security of tourists is not being studied by the future tourism bachelors or professionals who are being educated in tourism fields. Why?

One of the fathers of modern sociology, Emile Durkheim, defined education as the process of training skills in the workforce to play alternative roles which are necessary for the society. These roles are fulfilled by what the industrial machine offers. His main thesis was that education served to revitalize and keep social roles, as well as grant the "division of labor". The curricula express the legal permission issued by the state to perform a specific profession. The goal of education alludes to the convergence of individual abilities with a social mandate, which comes always from the economic production (Durkheim, 1956; 2012). Following this explanation, tourism bachelors and doctors are necessary in those societies where tourism plays a vital role in the economy, while they are ignored in others where the industry occupies marginal positions.

It is unfortunate that this doctrine does not apply to the case of tourism security, since the country has experienced diverse disasters and events which affected the activity. Despite the urgency that the issue has for tourism education, security and safety have not integrated the official syllabuses of academic courses. Certainly, tourism security is far away from being considered as a serious option to be incorporated into official education in tourism and hospitality careers.

To our knowledge, the questions of risk and education are inextricably intertwined to the cultural cosmology; this means how our being in the world is imagined. In his recent works, Jean Baudrillard defines the risk as a possibility, something that has not yet happened in the mediate experience. Employing the metaphor of minority report, where the "precogs" predicted exactly the crime before it has been committed, risks are mediating constructions which exert influences in the present, from the future (Baudrillard, 2006).

Following this, Korstanje (2014b) has pointed out in his recent paper, Why Risk-Research is More Prominent in English Speaking Countries in the Digital Society, that risks are social construes enrooted in the future to the extent they are carried by the process of communication. The impacts of risks, since they have not taken place while are disseminated by the media, are interpreted in diverse ways, taking the attention to the cultural matrix of each society. Anglo world is more sensitive to risk perception than Latin Americans or Spanish-speaking cultures. We have to trace a model towards two types of societies: risk-oriented societies and risk avoider societies. While some risk-oriented societies, such as the US or England, develop their technology to find and mitigate potential threats, others, underdeveloped, are not interested in the implementation of risk management plans. At time, we key the word disaster or desastre on Google, almost 3,110,000 entries are found in English, this is reduced to 1,400,000 in Spanish. The same applies for the term riesgo or risk. We traced almost 795,000 entries in English and 90,000 entries in Spanish. 
As has been formulated by Weber (1958), the spirit of Protestantism, as has already been examined by historians, has developed ways of productions which contrasted sharply to "Mediterranean societies". As a theological doctrine, Protestantism claimed that the salvation of soul was pre-determined by God. Human beings not only were unable to change their destinies, but also can only be limited to know if they were parts of the privilege uphill city. These few chosen people are marked by the book of salvation earlier than their birth dates. If you are doomed by God's grace, there is nothing you can do to avoid the fate imposed by the "lord". Unlike protestant reform, the Catholic Church encouraged the idea that heaven is available for all those who help the neighbor. Latin American cultures, based on the present acts, do not see the world as a hostile place. Therefore, the Catholic cosmology which determined Latin American character is not interested by the future, so risk is unimportant. The question of risk not only organized the economies in protestant cultures, but also closed the possibility of death. However, a much profound sociological explanation is needed here.

Based on the previous argument, Weber asserted the diagnosis but sited on the incorrect explanation. Capitalism, which is a future-oriented cosmology, derived from Norse mythology by means of protestant logic. The reform was strongly influenced by the ancient Norse mythology. This explains the reason why the Catholic Holland embraced the capitalist spirit in spite of its Catholic affiliation. The Norse mythology said that the Valkyries knew beforehand who will die in the battle ground. Delivered by Odin, they collected the soul of fallen warriors, to be brought to "heaven" (Valhalla). This tradition contrasted to the Mediterranean customs, where the tide of battle is defined in the present. Like protestant reformers, ancient Norse warriors believed in the power of future as the "cosmocrator" (creator) of human possibilities. This cultural dichotomy created two types of cosmologies to conceptualize the environment, representing diverse patterns of adaptation. While Anglo culture embraces the "preemptive paradigm" to colonize the future, accepting risk as a common exchangeable discourse, the Greco-Roman world avoided the future to be subject to the present. To our knowledge, this is the reason behind the adoption and over-abundance of risk maintenance programs, as well as formal post-graduate careers even doctorates in terrorism, risk, and disasters in the English-speaking countries.

\section{References}

Baudrillard, J. (2006). Virtuality and events: The hell of power. International Journal of Baudrillard Studies, 3(2), 1-11.

Durkheim, E. (1956). Education and sociology. New York, NY: Simon and Schuster.

Durkheim, E. (2012). Moral education. New York, NY: Courier Dover Publications.

Faulkner, B. (2001). Towards a framework for tourism disaster management. Tourism Management, 22(2), 135-147.

Floyd, M. F., \& Pennington-Gray, L. (2004). Profiling risk perceptions of tourists. Annals of Tourism Research, 31(4), $1051-1054$.

Kessler, G. (2009). El sentimiento de inseguridad: Sociología del temor al delito (The sentiment of insecurity: Sociology of fear of crime). Buenos Aires: Siglo Veintiuno Editores.

Korstanje, M. (2009). Re-visiting risk perception theory in the context of travel. E-Review of Tourism Research, 7(4), 68-81.

Korstanje, M. (2014a). Preface: Problems of tourism safety in Latin America. In P. Tarlow (Ed.), Tourism security (pp. 21-24). Waltham: Elsevier.

Korstanje, M. E. (2014b). Why risk-research is more prominent in English speaking countries in the digital society? International Journal of Cyber Warfare and Terrorism, 4(1), 8-18.

Korstanje, M. E., \& Clayton, A. (2012). Tourism and terrorism: Conflicts and commonalities. Worldwide Hospitality and Tourism Themes, 4(1), 8-25.

Korstanje, M. E., \& Olsen, D. H. (2011). The discourse of risk in horror movies post 9/11: Hospitality and hostility in perspective. International Journal of Tourism Anthropology, 1(3-4), 304-317.

Korstanje, M. E., \& Skoll, G. I. (2012). Nova York - Buenos Aires: Soluções diferentes para o mesmo problema. Terrorismo e Cidadania. Rosa Dos Ventos, 4(1), 40-58. 
Korstanje, M., \& Skoll, G. I. (2014). Points of discussion around 9/11: Terrorism and tourism revisited. E-Review of Tourism Research, 11(1-2), 1-17.

Quintal, V. A., Lee, J. A., \& Soutar, G. N. (2010). Risk, uncertainty, and the theory of planned behavior: A tourism example. Tourism Management, 31(6), 797-805.

Sunstein, C. R. (2002). Risk and reason: Safety, law, and the environment. Cambridge: Cambridge University Press.

Sunstein, C. R. (2005). Laws of fear: Beyond the precautionary principle (Vol. 6). Cambridge: Cambridge University Press.

Tarlow, P. E. (2000). Creating safe and secure communities in economically challenging times. Tourism Economics, 6(2), 139-149. Weber, M. (1958). Essays in sociology. New York, NY: Oxford University Press. 